\title{
Investigation and Analysis on the Development of Chinese Teachers in Vietnam University
}

\author{
Pham Thi Hong Tham ${ }^{1}$ \\ Zhang Yan Cheng ${ }^{2}$ \\ 1,2 Wuhan University College of Literature, China \\ Email:2732477103@qq.com
}

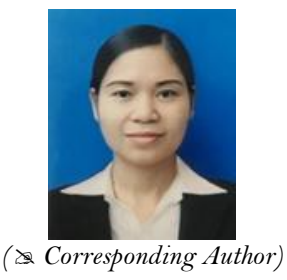

\begin{abstract}
In recent years, the expansion of relations with China has led to the increasing need for the use of employees knowing Chinese language. Today, Chinese language is not simply a necessary condition, but it also becomes a tool, an effective and powerful means to exchange and develop the Country. In the last 5 years, the number of students of Chinese language has increased dramatically, while the lecturers' have not increased, the new equipment has not been equipped, the curriculum has not yet completed, the regime of remuneration of the Country is not really attractive for talents, many teachers have not really tried to frequently participate in scientific research ... which made the teaching and learning Chinese difficult, especially in improving the quality of teaching. The results of many research projects showed that the number of Vietnamese graduate students who did not meet jobs' requirements occupied a very high ratio. Vietnamese students were often passive in learning and still weak in teamwork skills. In this study, we used the survey method using questionnaires and direct interviews. Through the results, we analyzed the factors from many different angles to find out causes of the above problems. At the same time, we also proposed some recommendations and resolutions for the current Chinese teaching and learning in Vietnam.
\end{abstract}

Keywords: Chinese teaching, Chinese teacher, Vietnamese, Education, Foreign languages, University.

Citation | Pham Thi Hong Tham; Zhang Yan Cheng (2019). Investigation and Analysis on the Development of Chinese Teachers in Vietnam University. Journal of Education and e-Learning in Vietnam University.

Research,
History:

Received: 10 January 2019

Revised: 14 February 2019

Accepted: 18 April 2019

Published: o July 9019

Licensed: This work is licensed under a Creative Commons

Attribution 3.0 License (cc)

Publisher: Asian Online Journal Publishing Group
Contribution/Acknowledgement: Both authors contributed to the conception and design of the study.

Funding: This study received no specific financial support.

Competing Interests: The authors declare that they have no conflict of interests.

Transparency: The authors confirm that the manuscript is an honest, accurate, and transparent account of the study was reported; that no vital features of the study have been omitted; and that any discrepancies from the study as planned have been explained.

Ethical: This study follows all ethical practices during writing.

\section{Contents}

1. Introduction

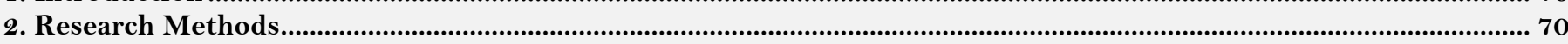

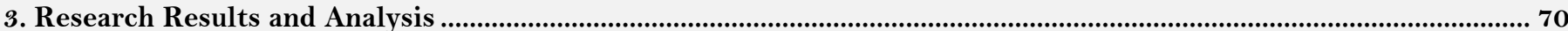

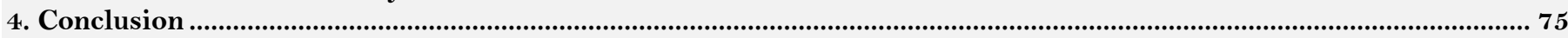

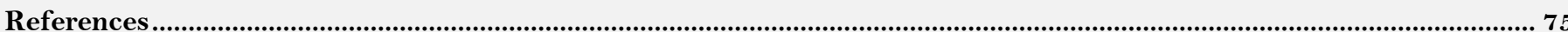




\section{Contribution of this paper to the literature}

This study contributes to the existing literature by investigating the overall situation and main problems of Chinese teaching in Vietnam.

\section{Introduction}

In 2019, there are 35 Universities in Vietnam open a new course such as the Chinese Language or Chinese teaching. The number of students enrolled each year is about 4.000 (Ministry of Education and Training of Vietnam, 2019). According to the Ministry of Education's forecast, there will be more and more universities offering Chinese language, and more college students choose to study Chinese (this data does not include Chinese selective course or Bilingual school who implemented Chinese as the second language).

College students who study Chinese continue to increase the series problems, such as the lack of teachers and the decline in teaching quality.

The results of recent studies show that although the study of Chinese college students does not meet the job requirements has declined, but still cannot meet the needs of society (Phung, 2018).

\subsection{Research Review}

In fact, in recent years, due to the country's development policy, Chinese research has been promoted. Some national and ministerial levels have been implemented, with some good results. Although the number of Chinese scientific research projects is large, most of them have covered all the research problems, but there is no overall planning and interconnection between them. Therefore, the research results cannot meet the actual requirements of teaching, and the depth of research cannot be satisfied. The overall conditions of academic study and the research value of various scientific research have not fully reflected (Phung, 2018).

\subsection{Research Target}

- Investigate the overall situation and main problems of Chinese teaching in Vietnam;

- Analysis of the main factors and causes affecting the development of Chinese teaching in Vietnam;

- Investigate the attitudes and perceptions of college teachers on Vietnamese Chinese teaching;

- Analysis of the main problems and influencing factors of the development of teachers in Vietnamese universities.

\subsection{Research Subject and Research Methods \\ 1.3.1. Research Subject}

The research subjects are Chinese teachers in various universities. Some of these teachers are Chinese language teaching majors; some are non-Chinese language teaching majors; both of them are our research objects. Through them, we can have a deep understanding of the current Chinese teaching in Vietnam.

To ensure the representativeness of the research, our survey adopts the method of stratified sampling. The stratified sampling considers three factors: geographical division, region type, and school type. The geographical division (north, central, southern) is represented by the first; (urban, rural, mountainous) with the second representatives; school type (foreign language school and non-foreign language school) with the third representatives. The random sample was taken from all 64 universities in Vietnam with Chinese language teaching. A total of 382 valid questionnaires were received, and the sample size was sufficient to ensure the reliability and scientificity of the results of the study.

\section{Research Methods}

\subsection{Questionnaire Method}

The questionnaire consisted of 32 questions divided into three parts. The first part is the necessary information of the applicants; the second part is the training procedures, courses, teaching methods, inspection and evaluation of Chinese teaching, and the third part is the participation of teachers in scientific research activities. The questionnaire was designed in Chinese to ensure that the teachers participating in the survey are Chinese teaching teachers. The polls are presented in a multiple-choice format to ensure that the teachers participating in the study can complete the education in high quality in a relatively short time.

\subsection{Data Collection Method}

We will send questionnaires according to the actual situation, or use e-mail, or distribute paper questionnaires to teachers face to face. A total of 382 valid questionnaires were returned. Personal interviews and surveys are conducted simultaneously. Depending on the actual situation, interview methods, including face-to-face interviews and telephone interviews, and some face-to-face interviews need to be scheduled in advance. Also, we have selected some relevant data and data from the Ministry of Education of Vietnam to ensure the reliability of this study. Quantitative analysis of the data results was performed using SPSS software, and the analysis of the conclusions was performed using a combination of quantitative and qualitative methods.

The data collection time is from October to December in the first semester of the 2018-2019 school year.

\section{Research Results and Analysis}

By 2019, there are 740 High Education platforms across Vietnam, and among them, there are 303 universities and colleges. There are 64 Chinese language teaching programs, 4 of them are opening Chinese major, 27 Chinese Language or Chinese Teaching. Other Schools' Chinese teaching is non-professional Chinese (Ruan and Zeng, 2016).

There are three types of Chinese national teaching in Vietnam: Chinese major; Chinese Language/Chinese teaching; Chinese selective course. 


\subsection{Chinese Learning Academic Standards}

The Ministry of Education of Vietnam stipulates that Chinese Language students in the college entrance examination can choose English or Chinese as their test language. Therefore, college students who study Chinese can enter the school on a zero basis. Although some students have already had a higher level of Chinese before going to college, some of them reached HSK level 4, level 5 or even level 6. In addition, some students have studied Chinese at the Foreign Language Center, and their Chinese level is relatively high. They can usually reach HSK3 or HSK4 and above. In addition, most other students have not been exposed to the Chinese language before going to choose Chinese major (Ding and Dan, 2016).

The level of Chinese proficiency after graduation is slightly different from different universities. However, in specialized foreign language colleges, college students receive professional and systematic Chinese teaching. Generally, they must pass HSK level 5 or above before graduation and also pass the final exam. The training program requires them to achieve a deep understanding of the relevant fields and be fluent in expressing their views and feelings, and be able to speak in scientific forums and academic conferences or to achieve professional translation. Students who choose the Chinese major need to reach HSK4 or HSK5 when they graduate at least, they can express their opinions or communicate with others in unfamiliar situations or they need to understand the basic content and express their opinions during basic meetings or scientific meetings. College students in Chinese selective course need to reach HSK3 or HSK4 and be able to express their opinions or communicate with others in familiar situations, but they are not required to reach the level of participation in scientific conferences (METV, 2018).

\subsection{Chinese Teacher Structure}

Under the total demand for national development, the Chinese teaching team in Vietnam has been expanding and the level of teachers has been continuously improved. According to the statistics of the Ministry of Education of Vietnam, in the 2017-2018 school year, there are 74.994 teachers in various universities in Vietnam, including 15.231 people $(20.3 \%)$ with a doctoral degree, $36.476(48.6 \%)$ master's degree, $729(0.97 \%)$ professor, and the associate professor has 4.538 (6.05\%) (METV, 2018). According to our survey, in the 2018-2019 school years, the proportion of professors with Chinese professorship was $3.4 \%$, that of associate professors was $7.1 \%$, that of a doctoral degree was $29.1 \%$, and that of master's degree was $43.7 \%$ Table 1 . Compared with the overall faculty level in Vietnam, the Vietnamese faculty teacher level is superior in all aspects.

Chinese Teacher Degree Statistics

Table-1. Teacher Degree.

\begin{tabular}{c|c|c|c|c|c}
\hline \multicolumn{2}{c|}{ Degree and academic title } & Amount & Percentage & Effective percentage & Cumulative percentage \\
\hline \multirow{4}{*}{ Effective } & Undergraduate & 64 & 16.8 & 16.8 & 16.8 \\
\cline { 2 - 6 } & Master's Degree & 167 & 43.7 & 43.7 & 60.5 \\
\cline { 2 - 6 } & Doctoral Degree & 111 & 29.1 & 29.1 & 89.5 \\
\cline { 2 - 6 } & Associate Professor & 27 & 7.1 & 7.1 & 96.6 \\
\cline { 2 - 6 } & Professor & 13 & 3.4 & 3.4 & 100.0 \\
\cline { 2 - 6 } & Total & $\mathbf{3 8 2}$ & $\mathbf{1 0 0 . 0}$ & $\mathbf{1 0 0 . 0}$ & \\
\hline
\end{tabular}

Every year, Vietnamese universities hold Chinese language training in Vietnam. At the same time, many Chinese teachers are sent to China to study Chinese or conduct scientific research. Many universities and research institutes require that the in-service teachers must raise their level of education within 5 years (such as master's degree from an undergraduate and doctoral degree from master's degree), otherwise they will be eliminated, so the university teacher obtains a master's degree or doctoral degrees is increasing. Specialized foreign language schools also use high degrees as the basic conditions for entry when recruiting teachers.

These requirements have a very positive effect on the one hand. Every teacher in the university strives to improve their academic level. Although most teachers' main motivation for improving their academic qualifications is to really improve their Chinese teaching level, there are also a few teachers who just want to avoid the relatively utilitarian attitudes that have been eliminated have made it difficult for them to have perfunctory situations in the process of learning, and even promoted the fake certificate industry in Vietnam. This phenomenon is also a national problem that Vietnam facing. The government has no good measures to deal with.

\subsection{The Use of Chinese Textbooks}

Regarding the use and writing of tutorials, most universities in Vietnam now specialize in writing Chinese courses for newly opened courses. For Chinese textbooks with existing courses, regular assessments and appropriate supplements will be used (Ruan, 2016).

Through the survey, we found that teachers' views on the use and writing of textbooks have changed a lot. According to the general view of modern language education, language courses and teaching materials should reflect the teaching characteristics of language skills training. $40.3 \%$ of the teachers in the survey affirmed that the textbooks they use are the textbooks that aim to develop language skills, but another $38.5 \%$ of teachers believe that they are using Chinese textbooks that aim to develop language knowledge, while $21.2 \%$ of teachers are not very clear about the type of Chinese textbooks they use Table 2.

Table-2. Editing of textbooks

Survey of the target system of teaching materials

\begin{tabular}{c|c|c|c|c|c}
\hline & Target & Amount & Percentage & Effective percentage & Cumulative percentage \\
\hline \multirow{3}{*}{ Effective } & Skill standard & 154 & 40.3 & 40.3 & 40.3 \\
\cline { 2 - 6 } & Knowledge standard & 147 & 38.5 & 38.5 & 78.8 \\
\cline { 2 - 6 } & Not obvious & 81 & 21.2 & 21.2 & 100.0 \\
\cline { 2 - 6 } & Total & $\mathbf{3 8 2}$ & $\mathbf{1 0 0 . 0}$ & $\mathbf{1 0 0 . 0}$ & \\
\hline
\end{tabular}


Based on the investigation of the previous curriculum system and the actual use of teaching materials, we found that although teachers generally agree with the language-oriented on language teaching system has a very welcome attitude; it indicates the Chinese teacher as the main reason of teaching. The group's understanding and cognition of the world's advanced language teaching viewpoints, which in itself represents a huge teaching progress, but from the use of textbooks as an important carrier and symbol of the actual teaching system, language knowledge is the main the proportion of textbooks in the framework is still not low, which is quite different from the previous teachers' judgment on its curriculum system. It also reflects the practical problems faced by Vietnamese Chinese teaching in the process of modern language teaching transformation. In addition, according to the teacher's evaluation, the learner-centered textbooks used in the textbooks accounted for $49.7 \%$, while the teacher-centered textbooks accounted for 38.2\% Table 3. Most Chinese teachers have noticed the learner-centered teaching philosophy, which echoes the previous findings.

Theoretical survey of teaching materials

Table-3. Use of textbooks.

\begin{tabular}{c|c|c|c|c|c}
\hline \multicolumn{2}{|c|}{ Materials } & Amount & Percentage & Effective percentage & Cumulative percentage \\
\cline { 2 - 6 } & For students to learn & 190 & 49.7 & 49.7 & 49.7 \\
\cline { 2 - 6 } & For teacher to teach & 146 & 38.2 & 38.2 & 88.0 \\
\cline { 2 - 6 } & Do not know & 46 & 12.0 & 12.0 & 100.0 \\
\cline { 2 - 6 } & Total & $\mathbf{3 8 2}$ & $\mathbf{1 0 0 . 0}$ & $\mathbf{1 0 0 . 0}$ & \\
\hline
\end{tabular}

In the actual teaching process, it is still difficult for most Vietnamese universities and Chinese teachers to design and write the Chinese language. Therefore, many colleges and universities choose to use Chinese textbooks published in China. The publication of Chinese textbooks in Vietnam now accounts for $67.8 \%$ of Chinese publications, while Vietnamese publications account for only $32.2 \%$ Table 4.

$$
\text { Table-4. Place of publication. }
$$

Place of publication of teaching materials

\begin{tabular}{c|c|c|c|c|c}
\hline \multicolumn{2}{c|}{ Place } & Amount & Percentage & Effective percentage & Cumulative percentage \\
\hline \multirow{3}{*}{ Effective } & Vietnam & 123 & 32.2 & 32.2 & 32.2 \\
\cline { 2 - 6 } & China & 259 & 67.8 & 67.8 & 100.0 \\
\cline { 2 - 6 } & Total & $\mathbf{3 8 2}$ & $\mathbf{1 0 0 . 0}$ & $\mathbf{1 0 0 . 0}$ & \\
\hline
\end{tabular}

\subsection{Teaching Methods}

Teaching methods occupy an increasingly important position in the teaching process. Table 3 shows that more than $80 \%$ of teachers believe that teaching methods play a very important role, $28.0 \%$ of teachers think it is important, and $42.9 \%$ think that it is more important, but Table 7 also shows that about $13 \%$ of teachers think that teaching methods are not important. Even $0.5 \%$ of teachers believe that teaching methods are very not important.

Importance of teaching methods

\begin{tabular}{c|c|c|c|c|c}
\hline \multicolumn{2}{|c|}{ Level } & Amount & Percentage & Effective percentage & Cumulative percentage \\
\hline \multirow{3}{*}{ Effective } & Very important & 107 & 28.0 & 28.0 & 28.0 \\
\cline { 2 - 6 } & Important & 164 & 42.9 & 42.9 & 70.9 \\
\cline { 2 - 6 } & More important & 60 & 15.7 & 15.7 & 86.6 \\
\cline { 2 - 6 } & Not so important & 49 & 12.8 & 12.8 & 99.5 \\
\cline { 2 - 6 } & Very unimportant & 2 & .5 & .5 & 100.0 \\
\cline { 2 - 6 } & Total & $\mathbf{3 8 2}$ & $\mathbf{1 0 0 . 0}$ & $\mathbf{1 0 0 . 0}$ & \\
\hline
\end{tabular}

The survey results show that the proportion of teachers who choose traditional speech-based teaching methods is only about $10.7 \%$, while the teachers who choose interactive methods for teaching accounted for $37.4 \%$. In addition, other modern teaching techniques have also received a great deal of attention from other teachers, such as $30.9 \%$ of the graphics method and $20.9 \%$ of the demonstration method. The survey results show that most teachers are aware of the importance of teaching methods and actively practice various modern teaching methods and teaching techniques.

The importance of teaching methods cannot be denied, but the best teaching method is still an inconclusive problem. However, according to modern teaching theory, most educational researchers and front-line teachers believe that student interaction is probably one of the best pedagogy, and traditional speech-based teaching methods have major drawbacks.

The survey from students shows that more than half of the college students said that they do not like the way teachers teach, that the teacher's teaching methods are too monotonous, the course is boring, and the mood is tense. In addition, teachers' teaching attitudes are also different from the students' learning needs. Some teachers are too strict, and some teachers are too serious and cause the classroom atmosphere to be dead. How to control anxiety in foreign language learning is an important issue. A stress-free environment can make language learners pay more attention to language learning and help students improve their language skills faster. In this regard, university students give teachers a lower score of only 3.42/5 points. From this point of view, although most teachers have been actively improving their teaching skills to match the most advanced modern educational concepts, the actual teaching skills of teachers have to be improved in light of the actual evaluation of students.

\subsection{Teaching Equipment}

The survey shows that most university students and teachers are dissatisfied with the school's teaching equipment, with $47.8 \%$ saying they don't like it and $19.1 \%$ saying it doesn't matter. 
In Vietnam's neighboring countries, schools have been equipped with a variety of modern teaching equipment. For example, all classrooms in China have modern teaching facilities such as computers, networks, projectors, and audio. Although many universities in Vietnam also have this equipment. However, in Vietnam, most of the equipment is old, and some are deteriorated and cannot be used. In the listening course, many schools still use voice recorders with poor voice performance, and even many teachers use their own equipment for the convenience of teaching. Most teachers are not satisfied with the equipment of the school.

\subsection{Chinese Teaching Curriculum System}

The most editorial has now noticed that learners learn Chinese content, based on modern teaching. Previously, most of the Chinese language teaching programs in Vietnam were centered on Chinese knowledge, which was based on knowledge transfer. The teaching objectives were based on behavioral teaching theory, with the knowledge system and teacher teaching as the center. Setting learners as passive knowledge recipients is not conducive to the overall improvement of students' Chinese skills.

Nowadays, the training program is more systematic, including not only the Chinese knowledge system but also the language skill standards, teaching resource allocation and curriculum evaluation system. It provides a total solution for the Chinese language teaching course and more importantly, the current training program focuses on Chinese skills and embodies the overall design philosophy of language communication skills.

The results show that $46.9 \%$ of the teachers surveyed believe that their curriculum system can reflect the training objectives, which is the training goal centered on Chinese skills training, while $13.4 \%$ of the teachers believe that their curriculum system is still centered on Chinese knowledge Table 6. Another 39.8\% of teachers believe that their system is a combination of two training objectives.

Table-6. Curriculum orientation.

Curriculum system orientation survey

\begin{tabular}{c|c|c|c|c|c}
\hline \multicolumn{2}{|c|}{ Levfective } & Amount & Percentage & Effective percentage & Cumulative percentage \\
\cline { 2 - 6 } & Knowledge standard & 51 & 13.4 & 13.4 & 13.4 \\
\cline { 2 - 6 } & Skill standard & 179 & 46.9 & 46.9 & 60.2 \\
\cline { 2 - 6 } & Two combinations & 152 & 39.8 & 39.8 & 100.0 \\
\cline { 2 - 6 } & Total & $\mathbf{3 8 2}$ & $\mathbf{1 0 0 . 0}$ & $\mathbf{1 0 0 . 0}$ & \\
\hline
\end{tabular}

According to the academic ability that students should have when they graduate, $20.2 \%$ of the teachers think that the school curriculum system is particularly suitable, $20.9 \%$ think it is good, $44.8 \%$ think it is better, most teachers think that the current curriculum system can meet the future employment needs of students, but $10.7 \%$ still think it is a bit poor, and $3.4 \%$ think it is particularly bad and can't meet the education goal at all Table 7 .

Table-7. Course System.

Course System Satisfaction Survey

\begin{tabular}{c|c|c|c|c|c}
\hline \multicolumn{2}{|c|}{ Level } & Amount & Percentage & Effective percentage & Cumulative percentage \\
\hline \multirow{3}{*}{ Effective } & Excellent & 77 & 20.2 & 20.2 & 20.2 \\
\cline { 2 - 6 } & Good & 80 & 20.9 & 20.9 & 41.1 \\
\cline { 2 - 6 } & Fair & 171 & 44.8 & 44.8 & 95.9 \\
\cline { 2 - 6 } & Bad & 41 & 10.7 & 10.7 & 10.6 \\
\cline { 2 - 6 } & Particularly bad & 13 & 3.4 & 3.4 & 100.0 \\
\cline { 2 - 6 } & Total & 382 & 100.0 & 100.0 & \\
\hline
\end{tabular}

\subsection{Chinese Teaching Evaluation}

Generally speaking, there are three main purposes for the evaluation of Chinese teaching: First, is to evaluate the effect of Chinese teaching; Second, is to adjust the Chinese teaching plan; Third, is to grade the students of Chinese major according to their level of Chinese. The survey shows that most teachers have recognized the importance of Chinese assessment. Among the several evaluation targets, the number of teachers who selected the evaluation target and the classification target was the most, occupied 34.6\%. Although the adjustment teaching plan is also an important evaluation target, only $29.8 \%$ of the teachers choose. In addition, $7.6 \%$ of teachers did not choose to evaluate the target, reflecting the unfamiliarity of this part of the teacher group.

The Ministry of Education of Vietnam invests a large budget each year to research and design Chinese language assessment projects and organizes many types of Chinese language teaching evaluation activities. All colleges and universities will actively cooperate with these evaluation projects, but the actual goals of the assessment are limited to assessing Chinese language proficiency. In itself, the student's grades will only remain on the teacher's teaching documents or be stored in computer files as a basis for the student's academic level at the end of the year, and will not really become the basis for student grading or adjustment of the teaching plan. Students with higher level will still sit in the same classroom as students with lower levels. The results of the survey show that although most teachers have realized the importance of teaching evaluation, the Chinese evaluation has a farreaching effect on teaching.

\subsection{Teaching Results}

Although from the graduation rate of the university, basically, $100 \%$ of the university students meet the requirements of graduation, however, $14.1 \%$ of the teachers in the survey expressed dissatisfaction with the students' Chinese academic performance, and the proportion of total dissatisfaction accounted for $12.8 \%$. Only $12 \%$ of teachers are satisfied with their students' academic performance Table 8 . Why would such a phenomenon happen?

According to the "Investigation and Analysis of Chinese Proficiency of Vietnamese College Students" (Pham, 2019) there are several main reasons: 
- There are too many students in each class, and the average number of students per class exceeds the world standard, which is 25 people in each class. Too many students in the classroom may reduce the chances of students practicing Chinese;

- The level of students' Chinese in the class varies, Making it difficult for teachers to choose the proper material of teaching progress and teaching methods;

- The teaching equipment is old and the teaching environment is not good enough to meet the learning requirements of the learners;

Graduation requirements are more employment orientation, which is not conducive to the development of students' practical Chinese skills.

Table-8. Teachers' opinions.

Satisfaction with students' Chinese learning level

\begin{tabular}{c|c|c|c|c|c}
\hline \multicolumn{2}{|c|}{ Level } & Amount & Percentage & Effective percentage & Cumulative percentage \\
\hline \multirow{3}{*}{ Effective } & Very satisfied & 46 & 12.0 & 12.0 & 12.0 \\
\cline { 2 - 6 } & Satisfaction & 156 & 40.8 & 40.8 & 52.9 \\
\cline { 2 - 6 } & Quite satisfied & 77 & 20.2 & 20.2 & 73.0 \\
\cline { 2 - 6 } & Not satisfied & 54 & 14.1 & 14.1 & 87.2 \\
\cline { 2 - 6 } & Totally dissatisfied & 49 & 12.8 & 12.8 & 100.0 \\
\cline { 2 - 6 } & Total & $\mathbf{3 8 2}$ & $\mathbf{1 0 0 . 0}$ & $\mathbf{1 0 0 . 0}$ & \\
\hline
\end{tabular}

\subsection{Scientific Research}

In today's society, the development of science and technology plays an increasingly important role in social development. In Vietnamese society, the development of science and technology has also played an increasingly important role. This survey shows that most teachers are very positive about scientific research. More than $90 \%$ of teachers believe that scientific research is an important task, and $36.4 \%$ of them believe that scientific research is very important Table 9. The ratio that is considered to be unimportant for scientific research is only less than $10 \%$.

Table-9. Status of Scientific Research.

Attitude towards scientific research

\begin{tabular}{c|c|c|c|c|c}
\hline & Level & Amount & Percentage & Effective percentage & Cumulative percentage \\
\hline \multirow{3}{*}{ Effective } & Very important & 139 & 36.4 & 36.4 & 36.4 \\
\cline { 2 - 6 } & important & 114 & 29.8 & 29.8 & 66.2 \\
\cline { 2 - 6 } & More important & 94 & 24.6 & 24.6 & 90.8 \\
\cline { 2 - 6 } & Unimportant & 24 & 6.3 & 6.3 & 97.1 \\
\cline { 2 - 6 } & Not at all important & 11 & 2.9 & 2.9 & 100.0 \\
\cline { 2 - 6 } & Total & $\mathbf{3 8 2}$ & $\mathbf{1 0 0 . 0}$ & $\mathbf{1 0 0 . 0}$ & \\
\hline
\end{tabular}

However, although the teachers' attitude towards scientific research is very positive, the actual number of people participating in scientific research is not many. $14.7 \%$ of the teachers have not participated in scientific research, and the proportion of teachers who seldom participate in scientific research is $45.3 \%$. The survey showed that among the teachers participating in various research projects, $46.9 \%$ participated in the school-level scientific research projects, and the department-level accounted for $21.2 \%$, while the proportion of teachers participating in the national and ministerial level only accounted for $9.4 \%$ and $7.9 \%$ respectively Table 10 . It can be seen that most teachers participate in scientific research projects at a relatively low level, and in the process of conducting scientific research, most teachers choose to study separately, and there is less cooperation among teachers. From the overall view, the Vietnamese national scientific research of Chinese language projects also lack planning and interconnection. Therefore, although the number of Chinese scientific research projects is large, the research results cannot meet the actual requirements of teaching, and the depth of research cannot meet the overall requirements of academic research. The research value of each scientific research has not been fully reflected.

Level of participation in research projects

Table-10. Research projects.

\begin{tabular}{c|c|c|c|c|c}
\hline \multicolumn{2}{|c|}{ Level } & Amount & Percentage & Effective percentage & Cumulative percentage \\
\hline \multirow{3}{*}{ Effective } & Country & 36 & 9.4 & 9.4 & 9.4 \\
\cline { 2 - 5 } & Ministerial level & 30 & 7.9 & 7.9 & 17.3 \\
\cline { 2 - 6 } & School & 179 & 46.9 & 46.9 & 64.1 \\
\cline { 2 - 6 } & Department level & 81 & 21.2 & 21.2 & 85.3 \\
\cline { 2 - 6 } & Not attending & 56 & 14.7 & 14.7 & 100.0 \\
\cline { 2 - 5 } & Total & $\mathbf{3 8 2}$ & $\mathbf{1 0 0 . 0}$ & $\mathbf{1 0 0 . 0}$ & \\
\hline
\end{tabular}

Based on reality, although there are more and more people learning Chinese language in Vietnam, teachers are relatively insufficient, but the income of teachers is still low. The monthly salary of a teacher who has just graduated from college is about 145 dollar a month, and the doctoral student who has 10 years of teaching experiences has a monthly salary of only 362 dollar, which makes each teacher need to get more income from the outside, earning money to support the family, and research needs a lot of time but less income, of course, it cannot be placed in an important position. Even if it is necessary to participate due to work reasons, most teachers will choose to make it easier, save money, and save time.

Therefore, scientific research is a very serious problem in the development of Chinese language teachers in Vietnam. The teacher team lacks the emphasis on scientific research, the proportion of teachers participating in scientific research is low, and the country and universities lack investment in scientific research. The Minister of Education of Vietnam also pointed out: "Although the number of studies is large, the research has covered many fields, but the research needs to be further deepened. The scientific research cooperation between schools needs to 
be strengthened, and there is still a lack of high-quality research results, which cannot meet the economic and social development and request" (Phung, 2018). The Vietnamese government should establish a dynamic mechanism to promote the development of teachers' research and encourage teachers to participate in scientific research, which is the shortcoming of the current government work. However, only by effectively improving the literacy of all aspects of the faculty, especially in scientific research, only then can truly promote the improvement of the quality of Chinese teaching.

\section{Conclusion}

Through this study, we can draw the following conclusions:

(1) Vietnamese Chinese language teaching is in a period of rapid development. More universities are offering Chinese language teaching, and the scale of students is expanding year by year.

(2) Chinese language teaching in Vietnam generally recognizes and implements a curriculum teaching system centered on language skills. Chinese teachers have a good understanding of modern concepts of language teaching and mastery.

(3) The actual situation of Chinese education is not entirely satisfactory. The Chinese teaching practice needs to improve more details, and the practical teaching skills of teachers need to be improved.

(4) Teacher development is a bottleneck affecting the development of Chinese language teaching in Vietnam. The critical factor affecting the growth of teachers is the overall planning and capital investment of the state for teachers.

The above research describes the actual situation of Chinese teaching in Vietnam. The scope of the survey is comprehensive, covering all 64 universities in Vietnam with Chinese majors, and the relevant conclusions are relatively reliable. The study also paid particular attention to the evaluation and cognition of Chinese teachers in Vietnamese colleges and universities. Although most Chinese teachers have a very positive attitude towards improving their Chinese teaching level and have a modern concept of language education, their practical Chinese teaching ability needs to be improved.

Many problems in Vietnam Chinese teaching not only have many realistic backgrounds and personal factors, such as the lack of teachers, the lack of teachers, the lack of professional appeal of Chinese teachers, the low enthusiasm of in-service teachers, and insufficient scientific research participation. However, it also shows that the government should further increase investment, strengthen overall planning, and strengthen cooperation with universities to start from improving the actual Chinese language ability of learners and improve the whole level of Chinese teaching in Vietnam.

\section{References}

Ding, T.H.L. and Y.M. Dan, 2016. A survey of Chinese students' motivation in Chinese in Ho Chi Minh city—also on the enlightenment of Vietnamese Chinese promotion. Overseas Chinese Education, 16(3): 668-675.

METV, 2018. Report data of university. Web Portal of Ministry of Education and Training of Vietnam.

Ministry of Education and Training of Vietnam, 2019. A handbook for highschool pupils: What need to know about enrolling the university, colleges in Vietnam, 2019. Vietnam Education Publishing House. [in Vietnamese], 45(1): 457-568.

Pham, T.H.T., 2019. Investigation and analysis of Chinese proficiency of Vietnamese college students. New Teaching Age, 27(12): 45-56.

Phung, X.N., 2018. University school year of 2017-2025 about development science and technology. Presented at the Conference, Hanoi. Ministry of Education and Training of Vietnam. [in Vietnamses].

Ruan, G.X., 2016. Investigation and research on the current situation of Chinese teaching in Vietnamese universities. Doctoral Dissertation, Suzhou University.

Ruan, W.Q. and X.Y. Zeng, 2016. Analysis of the status Quo of Chinese teachers in Vietnamese universities. Journal of Teaching and Research in Chinese, 15(3): 63-73. 